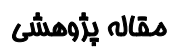

\section{طراحى و ساخت تن يوش الكتروكارديوكرام به منظور مانيتورينك فعاليت قلبى نوزادان}

\author{
محمدامين يونسى هروى'، عبدالرضا شاكرى'، سيدحسن سيد شريفى"
}

'كارشناس ارشد مهندسى يزشكى، كروه علوم بايه يزشكى، دانشعاه علوم يزشكى خراسان شمالى، بجنورد، ايران

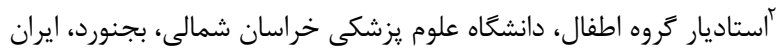

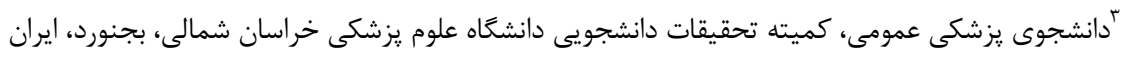

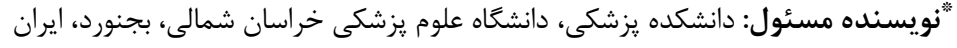

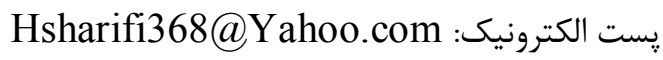

زمينه و هدف: بيمارى هاى مادزادى قلب يكى از هلايل عمده مركى و مير نوزادان مى باشد كه مشخصه ى اصلى آن انحراف ضربان قلب

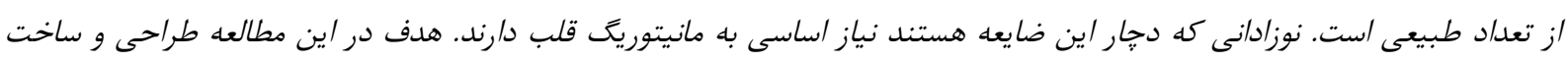

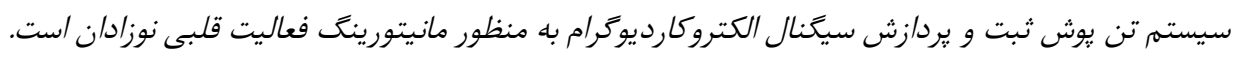

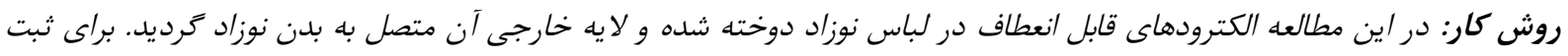
سيكنال دو الكترود در بازوى راست و جب و يكى در سمت راست شكم جاى داده شد. خروجى الكترودها وارد يكى تقويت كننده

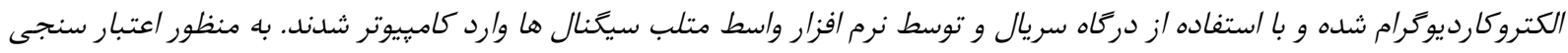

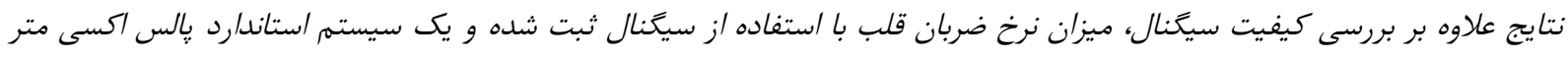

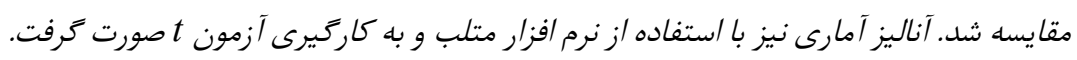

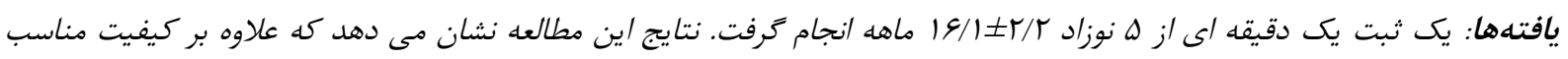

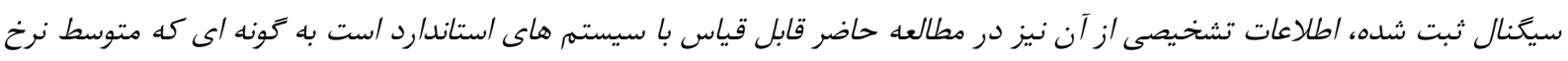

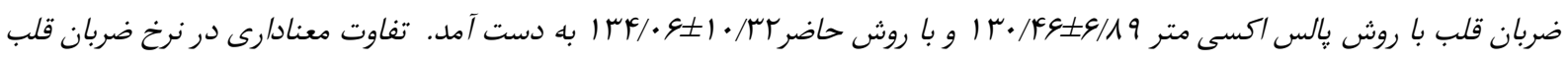

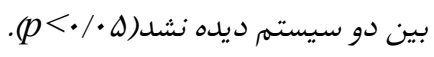
نتيجه كيرى: با استفاده از بكاركيرى سيستم طراحى شده مى توان رفتار فعاليت هاى قلبى نوزادان را به طور بيوسته اندازه كيرى و بر

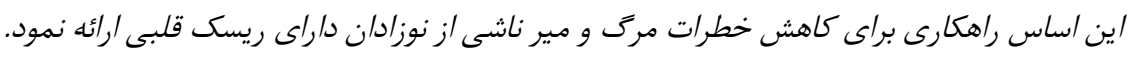

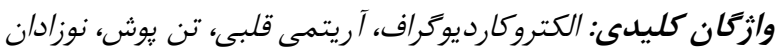

راستا، سيستمهاى يوشيدنى با قابليت مانيتورينگ بِيوسته

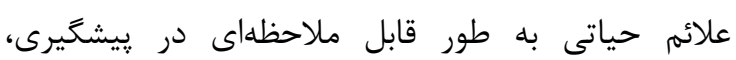
تشخيص به موقع، كنترل و درمان بيمارى مؤثر خواهند

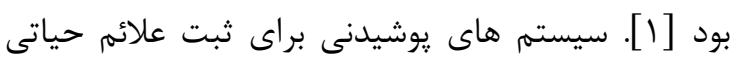

مقدمه امروزه كنترل و مراقبتهاى يزشكى توسط محدوده

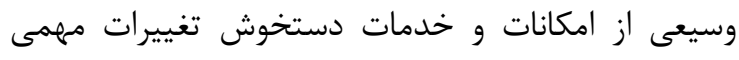
جون راههاى جديد مراقبت سلامت شده است. در همين 
در تشخيص، كنترل و جلوكيرى از اختلال شديدتر كمك آنا

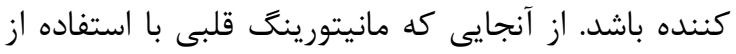
الكترودهاى ثبت الكتروكارديوكراف انجام مى يذيرد از اين

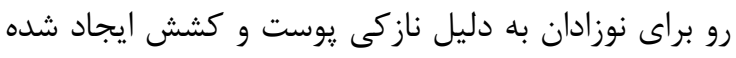
از جانب الكترودها در ثبت طولانى مدت توصيه نمى شونى شود. زيرا اين الكترودها در طولانى مدت باعث تحريك يوست و

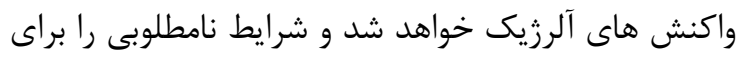

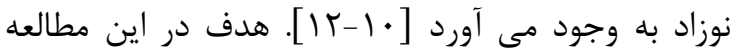
طراحى و ساخت سيستم تن يوش ثبت و يردازش سيخنال

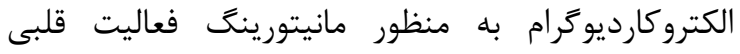

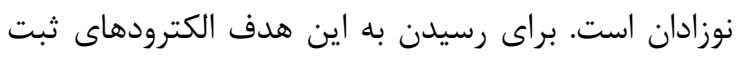
از نوع قابل انعطاف بوده و در بخش هاى مشخص در در تن ائ هدف يوش نوزاد تعبيه مى شود. با طراحى و ساخت مدارات

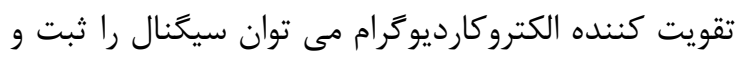
براى يردازش به كامييوتر ارسال نمود.

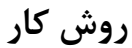
در اين مطالعه الكترودهاى قابل انعطاف لايه نازى كه به صورت خازنى طراحى شده اند در لباس نوزاد دوخته شده

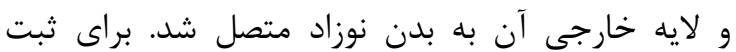

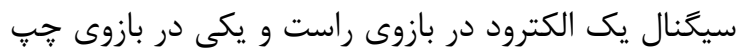

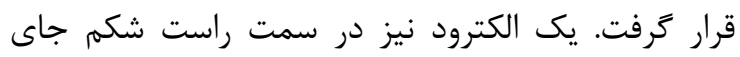

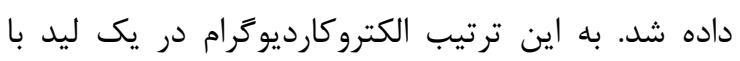
استفاده از سه الكترود كه در تن يوش نوزاد قرار مى كيرد، ثبت شد. شكل / مراحل طراحى تقويت كنينده الكتروكارديوكرام را براى ثبت سيكنال هاى قلبى نوراحت نوزادان نشان مى دهد. تقويت كننده طراحى شده در سازمان اختراعات ايران با شماره لو V919 به ثبت رسيده است.

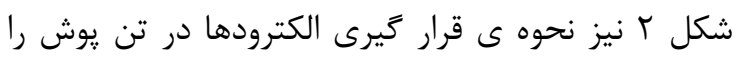

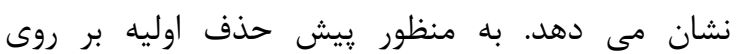

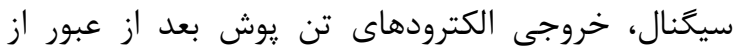

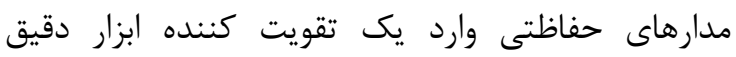

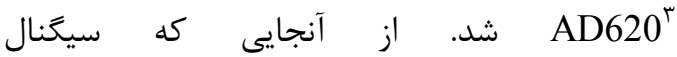

3-AD620: Low Power \& Low Drift Instrumentation Amp ANALOG DEVICES $\mathrm{CO}$

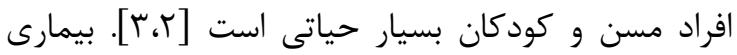
هاى مادرزادى قلب علت عمده مرك و مير نوزادان مى باشد. در مطالعات انجام شده، بروز بيمارى هاى مادرزادى

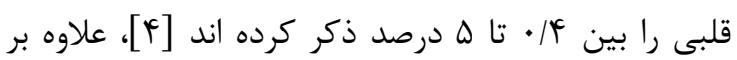

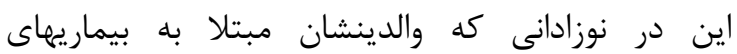
مادرزادى قلب هستند خطر بروز اين بيمارى ها بيشتر

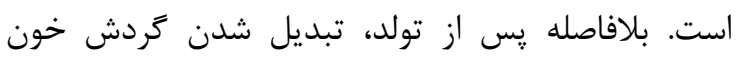

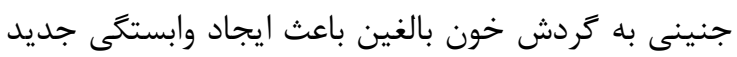

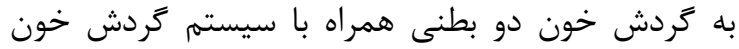
ريوى مى شوند، كه در نتيجه علايم بيمارى هاى

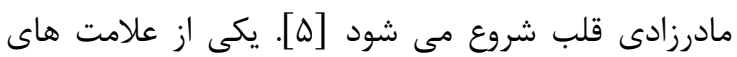

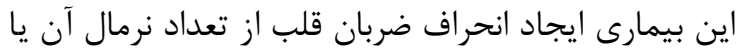
آريتمى مىباشد. در نوزادانى كه دجار اين ضايعه هستند،

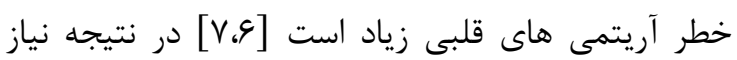

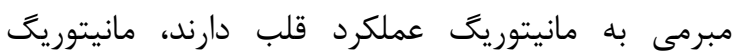
عملكرد قلب از نظر ميزان ضربان قلب ساده ترين روش ماند

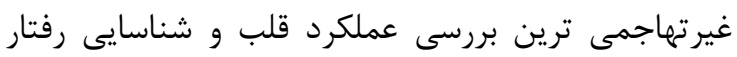

$$
\text { قلبى است [^- • 1] }
$$

نقص ديواره بين دهليزى (ASD) و ديواره بين بطنى (VD)

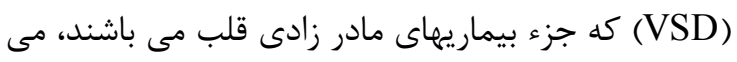

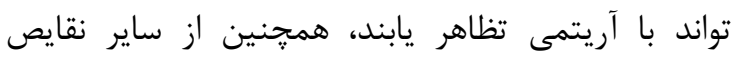

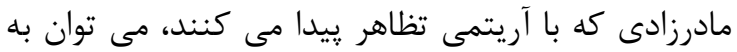

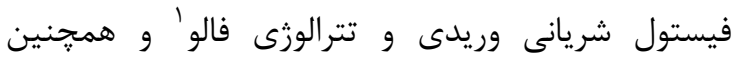

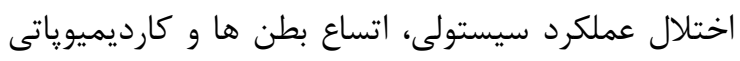

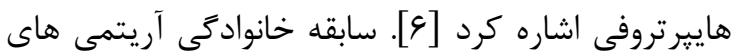

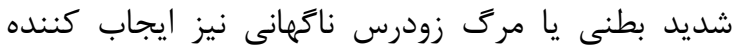

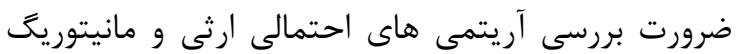
عملكرد قلب مى باشد، استفاده از روشهاى غيتى غير تهاجمى ارئى مانيتوريك قسمت مهمى از ارزيابى بيماران دجار آريتمى مى باشداء

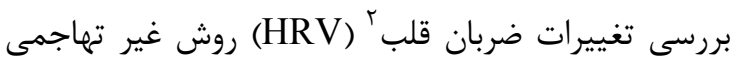
به منظور ارزيابى اثر سيستم عصبى خود كار قلب مى بـ باشد.

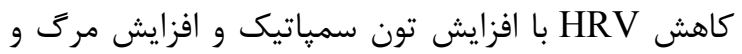

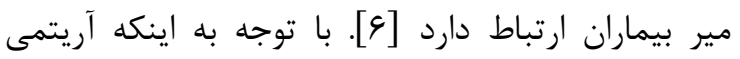

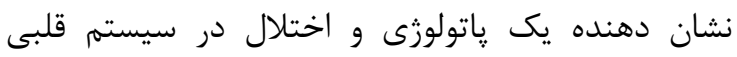
عروقى مى باشد، ارزيابى و مانيتورينگ مداوم آن مى تواند

1 -Tetralogy of fallot

2- Heart rate variability 


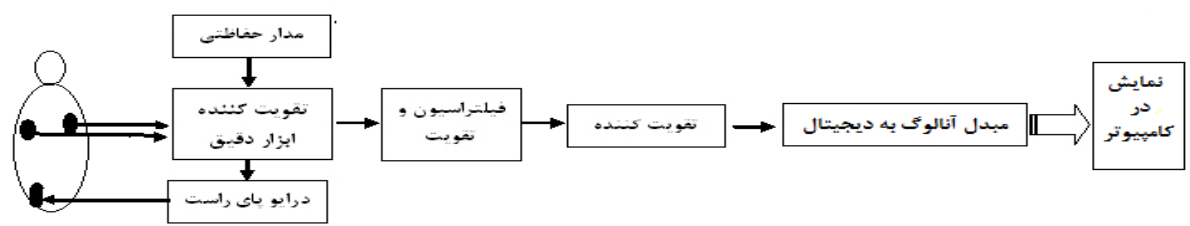

شكل ا: اجزاء تقويت كننده الكتروكارديوكرام براى ثبت سيكنال هاى قلبى نوزادان

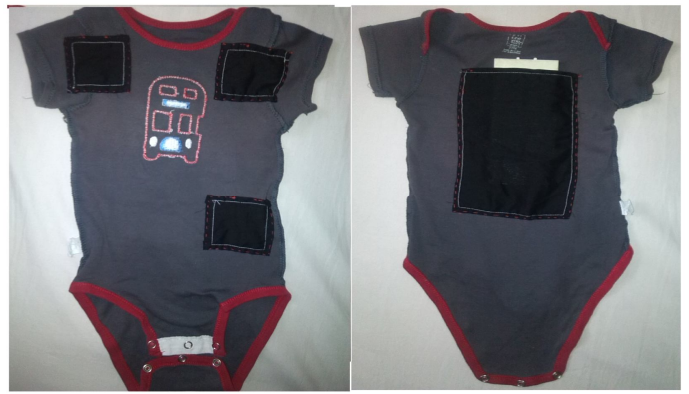

شكل r: نحوه قى قرار كيرى الكترودها در تن يوش نوزاد

از ورود دادهها به كامييوتر با فر كانس نمونه بردارى ..A

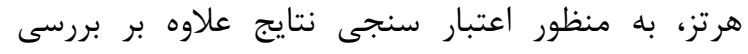

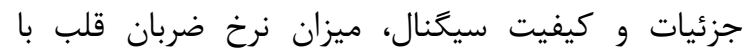
استفاده از سيخنال ثبت شده و يك سيستم استاندارد

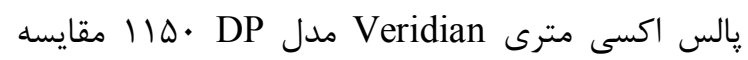

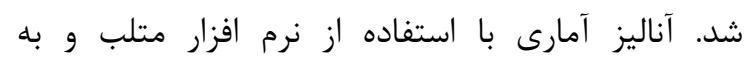

$$
\text { كار كيرى آزمون t صورت كرفت }
$$

يافته ها

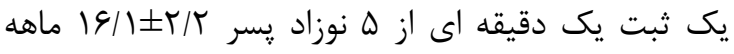

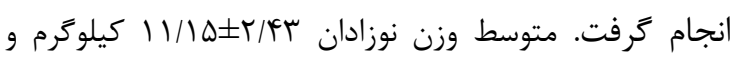
متوسط قد آنها نتايج ثبت سيخنال ها را براى يك نوزاد توسط سيستم

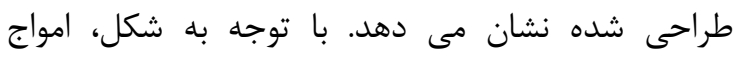

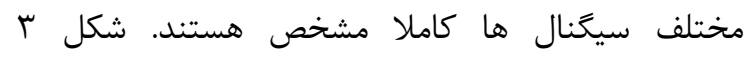

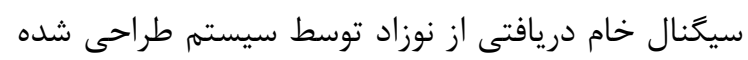

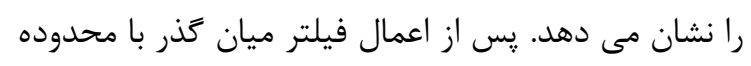

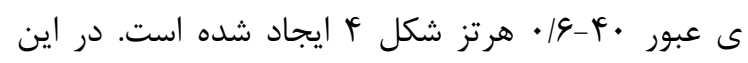

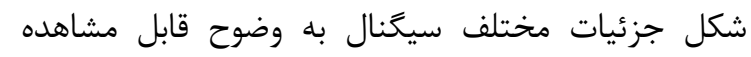

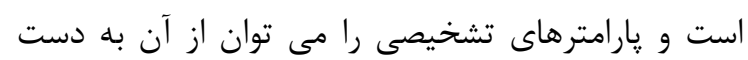
آورد. همان طور كه از شكل مشهود است كيفيت سيخنال

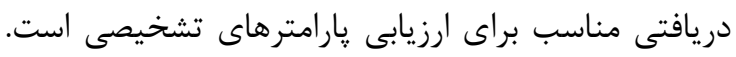
جدول ا نيز نتايج استخراج نرخ ضربان قلب و مقايسه آن آن
الكتروكارديوكراف داراى مولفههاى فر كانسى · تا فركانس • لها هرتز مىباشد، براى حذف اغتشاشات فر كانس بايين

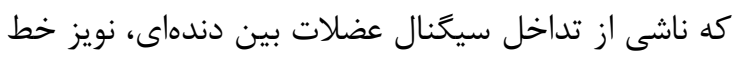

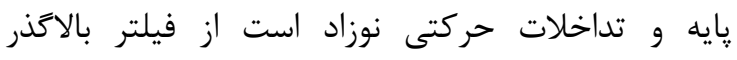

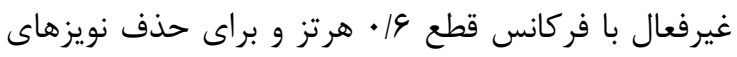

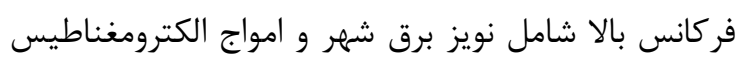

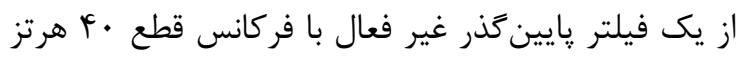

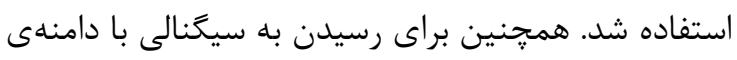

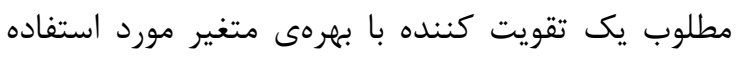

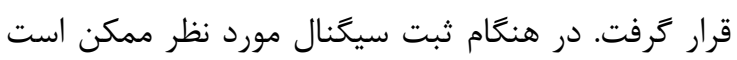

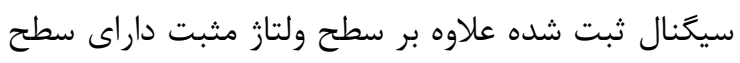

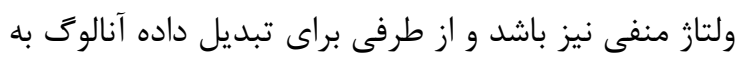

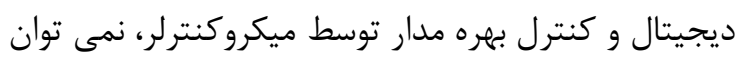

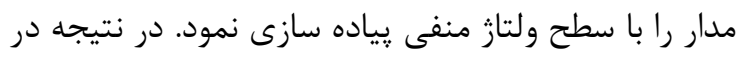

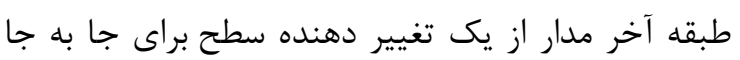

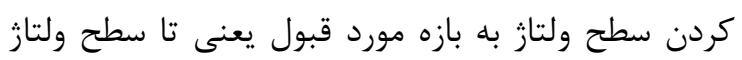

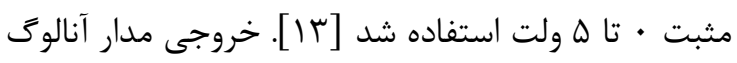

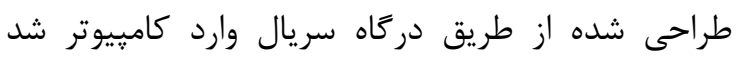

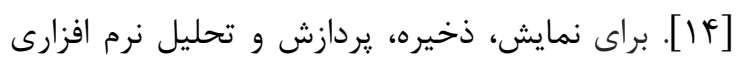

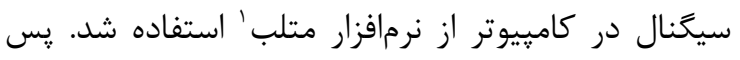

1 -MATLAB software version 2011a. 


\begin{tabular}{|c|c|c|}
\hline شماره سوزه & نرخ ضربان قلب باستادها از & نرخ ضربان قلب با استفاده تن يوش \\
\hline 1 & $|r| / r \mu \pm 9 \mid \cdot F$ & $1 T / / V q \pm 9 / 1 T$ \\
\hline r & $\| r \cdot \mid \Delta r \pm V / F \Delta$ & $\mid r \Delta / r r \pm \| / r q$ \\
\hline r & $\mid r V / r r \pm q / 11$ & $\|\digamma \Lambda / \mid r \pm\| r / \cdot V$ \\
\hline f & $|r q / V q \pm| r / .9$ & $1 Y N / V q \pm 9 / 1 T$ \\
\hline$\Delta$ & $|\digamma| / V \wedge \pm \Delta / \wedge \Lambda$ & $\|r q /\| \Psi \pm V / F F$ \\
\hline 4 & $1 r q / 11 \pm 1 \cdot / 1 f$ & $|r r / T| \pm \mid r / \Delta r$ \\
\hline متوسط & $\mid r \cdot / 49 \pm 9 / 19$ & $\mid M r / \cdot G \pm 1 \cdot / r r$ \\
\hline P-Value & &.$/ / r \Lambda$ \\
\hline
\end{tabular}

قياس با سيستم هاى استاندارد بوده و تفاوت هاى معنادارى بين نرخ ضربان قلب در طول زمان مشاهده نشد. همجنين كيفيت سيخنال مطالعه حاضر با پيش ير برداز مناسب شده به كونه اي كه امواج مختلف سيكنال قلبى در آن قابل مشاهده است. در اين يروزه، پاسخ فر كانسى كمى لهى

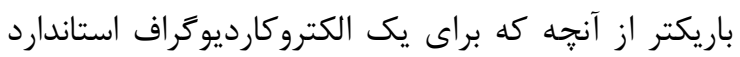

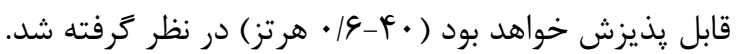
دليل اين امر آن است كه اغلب سيكنالهاى آرتيفكت

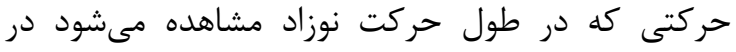

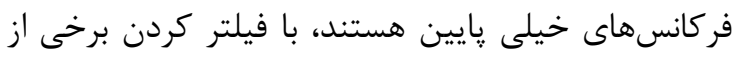

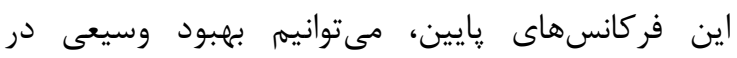

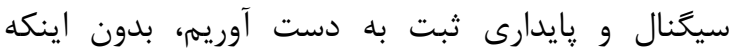

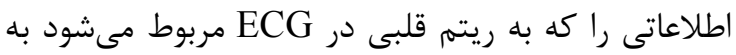
طور جدى تحت تا ثير قرار گيرد. تن يوش طراحى دانى شده

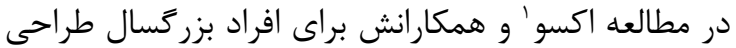
شده و داراى راحتى مناسب براى استفاده كنندكان است

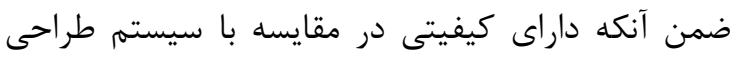

با مقدار مرجع را نشان مى دهد. ستون اول، شماره نوزادان و ستون دوم، نرخ ضربان قلب مرجع با استفاده از دستگًاه

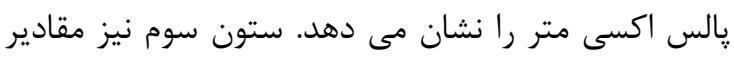
نرخ ضربان قلب با استفاده از سيكنال حاصل از تن يوش

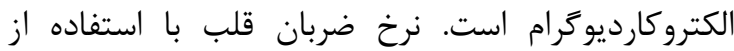

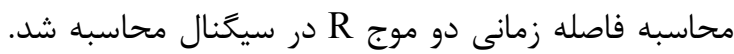

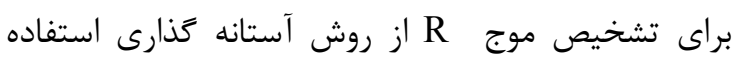

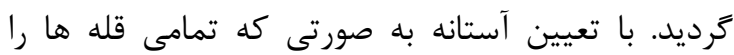
تشخيص دهد مى توان نقاط قله موج R را به طور خودكار

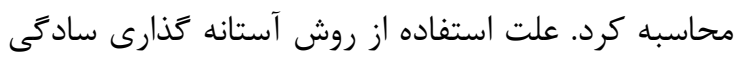

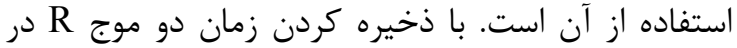

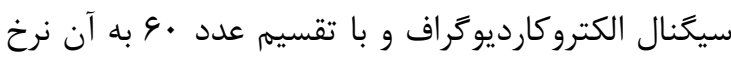
ضربان قلب محاسبه مى شود. بر اين اساس اختلاف معنادارى بين نرخ ضربان قلب در دو روش مشاهده نشد. هدف در اين مطالعه بررسى كارايى سيستم تن يوش دئ دان

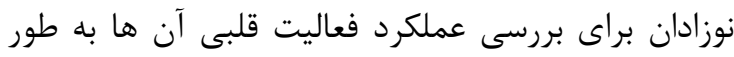
ييوسته بود. نتايج اين مطالعه نشان مى دهد كه بران اطلاعات

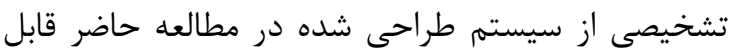




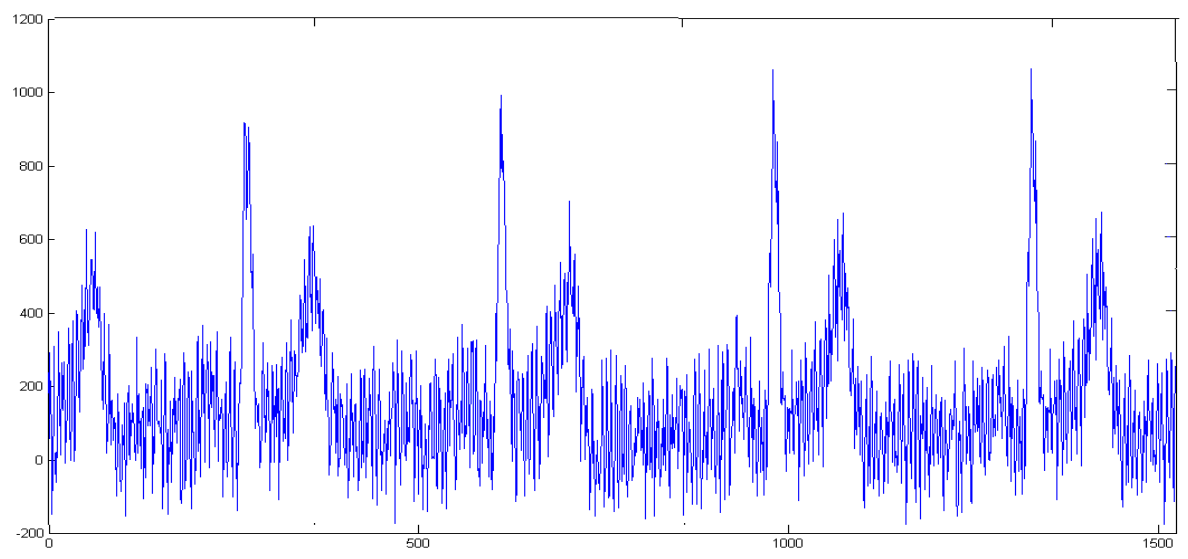

شكل זّ: سيكنال دريافتى سيستم طراحى شده با استفاده از تن يوش

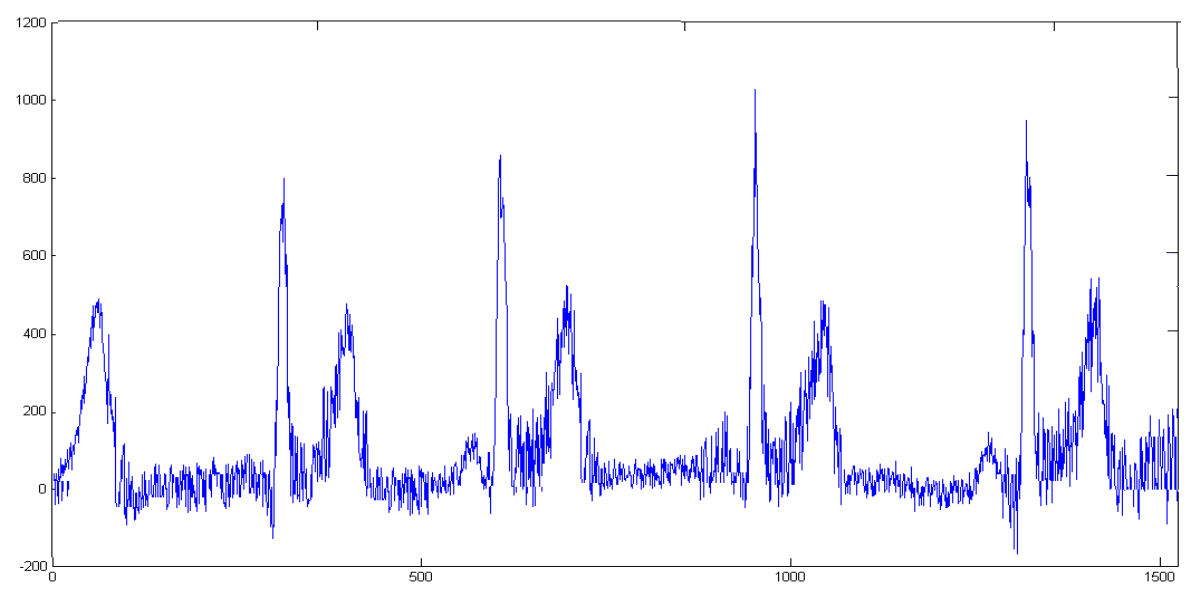

شكل †: سيحنال دريافتى سيستم طراحى شده با استفاده از تن يوش با فعال كردن فيلتر 9|• تا •

روش هاى مختلف و روش حاضر ديده نمى شود. اكرجه

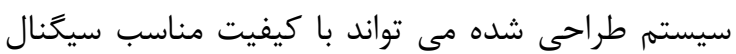
را دريافت نمايد اما براى داشتن سيخنال مناسب بايد حتما

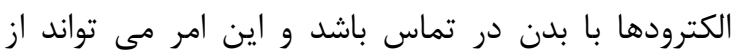
طريق لباس هاى كشى و تنگ تر در ناحيه سينه حاصل شود. براى استفاده از اين سيستم در نوزادان مختلف نيازمند لباس ها با سايزهاى مختلف هستيم تا الكترودها

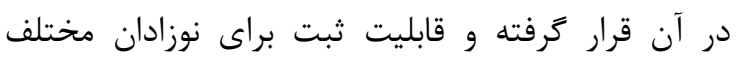
حاصل شود. علاوه بر اين براى اطمينان از اتصال الكترودها

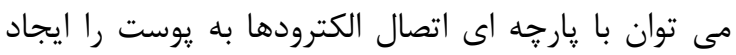

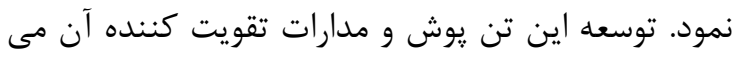
تواند علاوه بر نوزادان در سنين مختلف برائ سواى ساير افراد داراى ريسك قلبى مورد استفاده قرار گيرد. علاوه بر اين مى توان از طريق مازول هاى مختلف ارسال داده در
شده است [10]. سيستم طراحى شده اتن بيجر' و همكاران علاوه بر كيفيت مناسب سيحنال قابليت ارسال

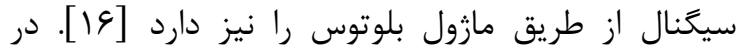

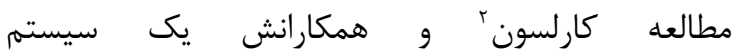

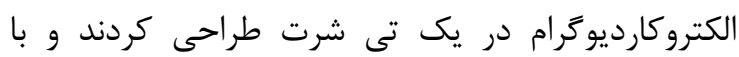
آزمايش آن در حالت هاى مختلف حركت و بدون حركت، كيفيت سيكنال را براى كارهاى تشخيصى خوب إن ارزيابى

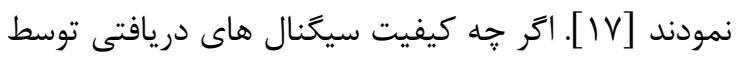

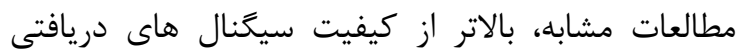

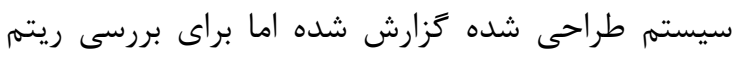

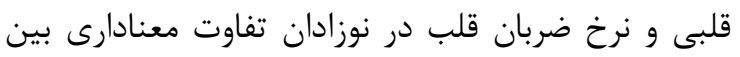

1- Ottenbacher

2- Karlsson 
استاندارد است به گونه اى كه متوسط نرخ ضربان قلب با

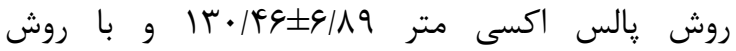
حاضر ץس/• | نرخ ضربان قلب بين دو سيستم ديده نشد (ه •/•>).

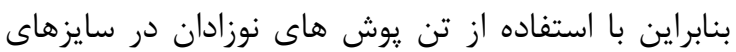
مختلف و بكارگيرى سيستم طراحى شده مى توان رفتار فعاليت هاى قلبى نوزادان را به طور ييوسته اندازه گيرى نمود و بر اين اساس راهكارى براى كاهش خطرات مرى و مير ناشى از نوزادان داراى ريسك قلبى ارائه نمود.

\section{References}

1. Webster JG, Medical instrumentation: apliction and design, Houghton Mifflin,boston, 1970 .

2. Huang WT, Chen $\mathrm{CH}$, Chang YJ, Chen YY, Huang JL, Ming C, "et al", Exquisite Textiles Sensors and Wireless Sensor Network Device for Home Health Care, 30th Annual International Conference of the IEEE Engineering in Medicine and Biology Society 2008:546-9.

3. Carta R, Jourand P, Hermans B, Brosteaux D, Vervust T, Bossuyt F, "et al", Design and implementation of advanced systems in a flexiblestretchable technology for biomedical applications, Sensors and Actuators : Physical 2009, doi:10.1016/j.sna.2009.03.012.

4. Julien I EH, Kaplan S, The incidence of congenital heart disease, Journal of the American College of Cardiology 2002; 39(12): 1890-1900.

5. Goldman L, Schafer A, Goldman's Cecil Medicine. 24th ed.New York:Elsevier, c2012:397-409.

6. Fauci AS, Longo DL, Hauser SL, Kasper DL, Loscalzo J, Jameson JL, Harrison's principales of internal medicine, 18th ed, New York:McGrawHill, 2012; 2:1920-1928.

7. Linti H, Horter P, Osterreicher, H. Planck, Sensory baby vest for the monitoring of infants, Proceedings of the International Workshop on Wearable and Implantable Body Sensor Networks (BSN`06), 2006

8. Coosemans J, Hermans B, Puers R, Integrating wireless ECG monitoring in textiles, Sensors and Actuators 2006; 13, 48-53.

9. Hertleer C, Grabowska M, Van Langenhove L, Catrysse M, Hermans B, Puers R, Kalmar A, Matthys D, The use of electroconductive textile material for the development of a smart suit,

$$
\begin{aligned}
& \text { دستگاه ساخته شده، سيگنال دريافتى از الكترودها را در } \\
& \text { فواصل دور و به صورت بى سيم نيز ارسال نمود. } \\
& \text { نتيجه گَيرى } \\
& \text { در اين مطالعه با استفاده از طراحى و ساخت يك تقويت }
\end{aligned}
$$

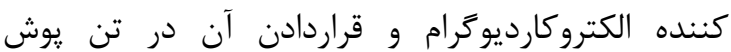

$$
\begin{aligned}
& \text { نوزادان، عملكرد قلب مورد ارزيابى قرار گرفت. نتايج اين } \\
& \text { مطالعه نشان مى دهد كه علاوه بر كيفيت مناسب سيخنال } \\
& \text { ثبت شده توسط سيستم طراحى شده، اطلاعات تشخيصى } \\
& \text { از آن نيز در مطالعه حاضر قابل قياس با سيسته هاى }
\end{aligned}
$$

World Textile Conference - 4th AUTEX Conference Roubaix, June2004; 22-24.

10. HOU L, Shuicai W, Yanping B, The Development of Embedded ECG Monitor Instrument, J of biomedical engineering, 2005; 24(6):418-420.

11. Catrysse R, Puers C, Hertleer L, van Langenhove $H$, van Egmond D ,Matthys, Towards the integration of textile sensors in a wireless monitoring suit, Sensors and Actuators, 2004; 114, 302-311.

12. Rossi D, Carpi F, Lorussi F, Mazzoldi A, Paradiso R, Scilingo EP, Tognetti A, Electroactive fabrics and wearable biomonitoring devices, AUTEX Res, J.2003;3: 180-185.

13. Zikic D, An improved reflective photoplethysmograph probe design for detection of an arterial blood flow, Med Eng Technol 2008; 32(1):23-29.

14. John E, Microcomputers and microprocessors the 8085,8086 , AVR programming 1989.

15. Xu L, Chen Z, Li Q, Application of the Wireless Digital Transmission Technology in Remote ECG Monitoring System, j CONTROL \& AUTOMATION, 2005;7:7-9.

16. Ottenbacher J,Romer S, Kunze C, Großmann $\mathrm{U}$, Stork W, Integration of a bluetooth based ECG system into clothing, in: Proceedings of the Eighth IEEE International Symposium on Wearable Computers (ISWC'04), Arlington, VA, 2004;3: 186-187.

17. Karlsson S, Wiklund U, Wireless Monitoring of Heart Rate and Electromyographic Signals using a Smart T-shirt, in International Workshop on Wearable, Micro and Nano Technologies for the Personalised Health, pHealth ,Valencia, 2008. 
Original Article

\title{
Design and construction of wearable electrocardiogram to monitor cardiac activity in infants
}

\author{
Younessi Heravi $M A^{1}$, Shakeri $A R^{2}$, Seyed sharifi $S H^{3 *}$ \\ ${ }^{1}$ M.Sc of Biomedical engineering, Department of Basic Sciences, Medicine School North Khorasan University \\ of Medical Sciences, Bojnurd, Iran. \\ ${ }^{2}$ Assistant professor of pediatrics, North Khorasan University of Medical Sciences, Bojnurd, Iran. \\ ${ }^{3}$ Student Research Committee, School of Medicine, North Khorasan University of Medical Sciences, Bojnurd,
} Iran.

*Corresponding Author:

Student Research Committee, Medicine School, Shahriar St, Bojnurd North Khorasan, Iran. Email:

Hsharifi368@Yahoo.com

\begin{abstract}
Background: Congenital heart disease is a major cause of infant mortality and its main characteristic is deviation of heart rate than normal. Heart monitoring is the basic requirement in infants with this disease. To evaluate cardiac function and behavior, the simplest method is cardiac monitoring. The aim of this study was to design and construct a wearable system with electrocardiogram signal processing for monitoring heart activity.
\end{abstract}

Methods: In this study, flexible electrodes in the external layer of baby clothes were sewed and attached to the arm. One electrode was also placed in the right abdomen. Signals were continuously recorded through a serial network communication by an external personal computer. A software interface was used to display and process the signals in the computer. To validate results, the heart rate was obtained by the designed system and spo 2 system. Statistical analysis was performed by using the test in MATLAB software.

Results: In this study, 5 babies (2/2 \pm 1/16-months) participated. The results show that the signal quality and the diagnostic information by the wearable system were comparable with standard systems. The mean heart rate by designed system was $130.46 \pm 6.89$ and $134.06 \pm 10.32$ by spo 2 system. There was no significant difference in heart rate between the two systems $(p<0.05)$.

Conclusion: Using the wearable system can monitor cardiac activity continuously and Based on this system present a mechanism to reduce the risk of infant mortality from cardiovascular risk.

Keywords: electrocardiograph, wearable system, cardiac arrhythmia, infants. 